\title{
Mechanisms of Memory Enhancement
}

\author{
Sarah A. Stern ${ }^{1,2}$ and Cristina M. Alberini ${ }^{2}$ \\ Cristina M. Alberini: ca60@nyu.edu \\ ${ }^{1}$ Friedman Brain Institute, Graduate School of Biological Sciences, Mount Sinai School of \\ Memories \\ ${ }^{2}$ Center for Neural Science, New York University
}

\begin{abstract}
The ongoing quest for memory enhancement is one that grows necessary as the global population increasingly ages. The extraordinary progress that has been made in the past few decades elucidating the underlying mechanisms of how long-term memories are formed has provided insight into how memories might also be enhanced. Capitalizing on this knowledge, it has been postulated that targeting many of the same mechanisms, including CREB activation, AMPA/ NMDA receptor trafficking, neuromodulation (e.g. via dopamine, adrenaline, cortisol or acetylcholine) and metabolic processes (e.g. via glucose and insulin) may all lead to the enhancement of memory. These and other mechanisms and/or approaches have been tested via genetic or pharmacological methods in animal models, and several have been investigated in humans as well. In addition, a number of behavioral methods, including exercise and reconsolidation, may also serve to strengthen and enhance memories. By capitalizing on this knowledge and continuing to investigate these promising avenues, memory enhancement may indeed be achieved in the future.
\end{abstract}

\section{Those who cannot remember the past are condemned to repeat it. - George Santayana}

Memories are a fundamental part of our identity. As highlighted by the quote above, memories guide our behavior at every moment by reminding us of our past actions and their outcomes. For those individuals whose capacity to form memories is disrupted, life becomes increasingly difficult and isolating. The cognitive dysfunction associated with many debilitating diseases, including Alzheimer's disease (AD), diabetes, Parkinson's disease (PD), and even in aging, demands effective therapies that can lead to recovery of memory functions or memory enhancement.

One strategy that may lead to the identification of memory enhancers is to capitalize on the knowledge gained by the biological study of long-term memory formation and storage. In the last two decades, extraordinary progress has been made in the understanding of the cellular and molecular mechanisms that are used for memory formation in several different species and types of learning. Results from these studies have left us with core knowledge about the role of conserved gene expression pathways, such as those regulated by the cAMP response element-binding-CCAAT enhancer binding protein (CREB-C/EBP) transcription factors ${ }^{1}$. In parallel, cellular and electrophysiological investigations have led to the discovery of long-term potentiation (LTP) and long-term depression (LTD) which provide

Correspondence to: Cristina M. Alberini, ca 60 @ nyu . edu. 
cellular models for testing mechanisms of plasticity associated with memory formation ${ }^{2}$. Disruption of these mechanisms has pointed to useful approaches and targets for the development of therapies that attenuate obtrusive memories, such as those contributing to post-traumatic stress disorder (PTSD), phobias, and drug addiction ${ }^{3}$. On the other hand, the identification of mechanisms that can amplify, enhance and/or strengthen synaptic plasticity represents potential therapeutic tools for enhancing adaptive memories and contrasting the onset and progression of disorders of cognitive functions.

The focus of this Review is to provide an overview of the treatments that have been reported to promote memory enhancement and, where known, their underlying mechanisms. Particular attention will be given to the description of the various stages of learning and memory storage that can be targeted for enhancement as well as the different forms of memories that can be enhanced. First, we will summarize the basic knowledge underlying learning and memory that is relevant for discussions pertaining to memory enhancement. We will then review mechanisms of memory enhancement found with various substances/ approaches, focusing on which types and stages of memory are enhanced in both animal models and human subjects. Given the vast literature on pharmacological compounds or approaches that modulate memory, it is not feasible to discuss every possible route to cognitive/memory enhancement; however, it is our intent to summarize the major findings obtained with pharmacological, neuromodulatory and behavioral methods. Moreover, we do not provide a comprehensive knowledge of memory enhancement obtained in transgenic models, with a few exceptions that are pertinent to the topics of this review. We thus refer to excellent and exhaustive reviews for genetic approaches to memory enhancement ${ }^{4,5}$.

\section{Defining Memory and Targeting Phases for Memory Enhancement}

\section{Stages of Memory Formation and Storage}

Since Ebbinghaus conducted his famous studies in memorizing nonsense syllables ${ }^{6}$, it has been universally recognized that memory consists of multiple stages, including acquisition/ encoding, working memory/short-term memory, long-term memory/consolidation, memory retrieval, and reconsolidation (see Box A for detailed description of memory stages).

Acquisition/Encoding is the initial stage of memory formation in which the subject learns something new (ie. acquires information). This process requires that the subject be attentive, and that there be no retroactive or proactive interference that occlude learning of the current information. Working memory refers to the holding of information online in order to keep processing additional information, whereas short-term memory is the ability to hold the given information offline in mind for a given period. Short-term memory (STM) thus refers to memories that are held in mind for a relatively short period of time - seconds to minutes (ie. remembering a phone-number until you can write it down) ${ }^{7}$. This differs from long-term memory, which can hold information for long periods of time, without a predefined limit on the quantity of information held.

Long-term memories (LTM), in fact, can last for days, months, years, even a lifetime. The process that transforms the learned information into LTM is known as memory consolidation, the process that accompanies the transition from a labile memory to one that is stable and resistant to disruption. This transition requires a number of molecular, cellular and structural changes that occur over time, with some completing over hours or days and others extending over weeks, months or perhaps even years; once those events are completed, the memory is considered stable or consolidated ${ }^{8}$. If any of the phases underlying consolidation is disrupted, memory is lost. Finally, retrieval is the process of recalling a memory. A challenge for studies aiming to identify the mechanisms of memory consolidation is the difficulty in discerning whether a memory deficit lies in the 
consolidation process (ie. the memory was never formed or was eliminated) or the retrieval process (ie. the memory is stored but cannot be retrieved, or recalled). Furthermore, it is likely that substances that enhance retrieval might be clinically beneficial, yet this stage of memory has received little attention thus far. Importantly, both the number and modality of retrievals can influence memory consolidation and storage.

In the 1960's, and later again around the year 2000, it was shown that retrieval of a memory that has become resilient to the initial molecular interference initiates another round of consolidation as, in fact, this retrieved memory becomes again temporarily labile, and undergoes a re-stabilization process in order to be maintained ${ }^{9}$. This re-stabilization is known as reconsolidation. The function of reconsolidation is still being debated, however, one compelling hypothesis is that it facilitates memory strengthening, an intriguing outcome which will be discussed in further detail below.

Why is it important to differentiate these different stages of memory in the context of discovering memory enhancers? Cognitive dysfunction can result from impairments in one or more of these stages, and is it thus critical to identify stages can be selectively or better targeted for the most efficacious cognitive therapy. For example, a substance that enhances attention may increase the probability of the information being encoded successfully, and therefore may enhance the memory ${ }^{10}$. Additionally, a prominent symptom of the devastating $\mathrm{AD}$ seems to be the inability to consolidate long-term memories, as a gradient of retrograde amnesia accompanies AD progression ${ }^{11,12}$. However, many AD patients also have attention deficits, which would in turn cause a problem with the initial encoding ${ }^{13}$. This is particularly true also for PD patients, where deficits in attention and executive control are the paramount cognitive impairments ${ }^{14}$. But even without the extremes of these devastating pathologies, in healthy individuals - particularly with aging - a common complaint is not being able to "remember" well enough, which commonly refers to the inability to retrieve memories ${ }^{15}$, though it is not entirely clear where the exact impairment in normal aging lies ${ }^{16}$. Thus, in an experimental setting, it is important to consider which stage of memory a putative memory enhancer is affecting. This is relatively straightforward via pharmacological means, which can be administered at any time point, before or after training or retrieval. Genetic or molecular approaches represent other means to manipulate memories, and different behavioral tasks may be tested to get a sense of which stages are affected by the manipulation, for example working memory tasks vs. long-term memory tasks (See Box A for descriptions of common tasks used for these purposes). Undoubtedly, all behavioral, pharmacological and molecular approaches represent important levels of investigation that, in combination, can provide a better understanding of mechanisms of memory formation and enhancement.

\section{Types of Memories and Memory Systems}

Memories can be classified not only in a temporal manner, but also according to their type and function, as well as by which brain regions underlie their formation and processing ${ }^{17}$. The view that memories could be anatomically localized has been long disputed. A landmark discovery in this area was that of Brenda Milner who studied the memory deficits of a patient known as H.M. Due to severe epilepsy, H.M. underwent a bilateral medial temporal lobe resection and, while he emerged fully treated from the epilepsy, he developed profound memory deficits that were mostly restricted to the formation of long-term explicit memories. Studies conducted with H.M. and other patients with selective brain damage suggested that there are numerous memory types that can exist independently, but often interact $^{18}$ (Figure 1). Explicit - or declarative - memories, which were disrupted in H.M., can be either semantic (referring to memories of facts or concepts ie. your date of birth) or episodic (referring to memories of events ie. your birthday party), and are subserved primarily by the medial temporal lobe, particularly by the hippocampus. Moreover, there are 
implicit types of memories, the memories of how to do things, which critically involve motor learning, such as skiing, playing piano, or riding a bicycle. One type of implicit memory is the memory formed as a consequence of simple associative learning; when the associations are emotional, (i.e. between a neutral stimulus and a stimulus with a valance, either aversive or rewarding), the learning relies primarily on the amygdala. When the associations produce reflexive skeletal responses, as in the case of delay eyeblink conditioning, the learning relies primarily on the cerebellum. A more gradual type of implicit learning that results in the formation of motor skills and habits relies primarily on the striatum.

Importantly, these memory systems are not separated in nature, acting alone and on one type of memory, but rather, they coexist and often interact. For example, inhibitory avoidance and contextual fear conditioning memories that are commonly used in rodent memory studies (see Box A for description of behavioral tasks) involve multiple brain regions and multiple types of memories. In fact, these tasks require, for example, both an emotional, implicit component, mediated by the amygdala, and a contextual, explicit component mediated by the hippocampus. Similarly, by shifting certain parameters such as cueing specific arms or providing enriched contextual cues, the same radial arm maze with food reward (see Box A for a detailed description of task) can be used to train animals to visit specific arms by very different strategies, mediated by either amygdala, hippocampus, or striatum ${ }^{19}$. Thus, depending on task demands, various structures may be engaged to process what seems like identical information (ie. that a number of arms contain food) in different ways, producing different kinds of memories.

For the purposes of developing memory enhancers, it is important to note that in cognitive impairments associated with $\mathrm{AD}$ or aging-related cognitive decline, the most vulnerable memories are those same memories that were lost in H.M. Implicit memories are very often spared, or at the very least, impaired at the last stages of the disease. Thus, there is an urgent need to identify therapies that target impairments of hippocampal-dependent memories.

However, as mentioned above, impairments associated with PD are often linked to working memory and executive control, and thus discovering mechanisms of enhancement for those disorders are equally important.

Importantly, it is critical to keep in mind that there might be several drawbacks with the use of cognitive enhancers; for example the effect could be non-selective enhancement, as a drug that enhances synaptic plasticity may result in the enhancement of both adaptive and maladaptive memories. Another drawback could be that memories are enhanced but become rigid and inflexible, or cognitive stimulants may lead to hyperactivation and seizure. Thus, while enhancement of in vitro synaptic plasticity and excitability is a useful tool for establishing physiological effects of various substances, it is always necessary to comprehensively investigate all possible effects using in vivo treatments and behavioral as well as physiological measures, as they provide the most compelling evidence of which approaches will be most effective in clinical populations.

\section{Mechanisms of Memory Enhancement}

\section{Gene Expression: The CREB-C/EBP Pathway}

One of the first mechanisms identified as critical for long-term memory consolidation (both explicit and implicit) is the requirement for de novo protein and RNA synthesis ${ }^{20}$. Similar requirements have been found for long-term plasticity, including long-term facilitation in Aplysia californica and a phase of LTP that lasts more than one hour, known as late-LTP (LLTP $)^{1}$, though not all late forms of LTP appear to share this requirement ${ }^{21}$. Many years of discussions have debated the functional effects of protein synthesis inhibitors used in many 
experiments, and we refer to this literature for questions, outcomes and debates 22,23 . Regardless, the findings that in addition to pharmacological approaches molecular and genetic methods have provided evidence that transcription and translation are essential for memory, led to the subsequent discovery of important, evolutionarily conserved pathways required for long-term memory formation: that regulated by the transcription factors CREB and C/EBP (Figure 2). CREB is activated by numerous signal transduction pathways implicated in memory consolidation and enhancement, from growth factor stimulation of tyrosine kinase receptors coupled to the activation of Ras and extracellular signal-regulated kinase (ERK); to G-Protein Coupled Receptor (GPCR) activation coupled to activation of adenylyl cyclase, increase in cAMP, and activation of protein kinase A (PKA); to the activation of stress pathways and glutamate release leading to release of intracellular calcium and relative downstream events. All of these pathways can lead to the activation of an activator form of CREB, CREB1. This activation in turn can lead to the transcriptional regulation of a number of target genes, including immediate early genes (IEG). Some IEGs are transcription factors, which regulate the expression of effector genes that are thought to participate in downstream synaptic changes underlying synaptic plasticity. This is, for example, the case with the IEG/transcription factor C/EBP $\beta$, a CREB-regulated target gene required for memory consolidation ${ }^{1}$.

Disrupting CREB1 results in memory deficits, while augmenting CREB1 activation results in memory enhancement. The first demonstrations that CREB plays an essential role in both the disruption and enhancement of memory consolidation came from studies in invertebrates, namely Aplysia californica and Drosophila melanogaster. In Aplysia, Bartsch et al. ${ }^{24}$ reported that the disruption of ApCREB1, the Aplysia homolog of mouse CREB1 leads to an impairment in long-term facilitation (a cellular model of long-term memory in Aplysia), and that the interference of a repressor form of CREB, ApCREB2, induces a longterm facilitation response from training protocols that would normally only produce shortterm facilitation. In parallel studies, Yin et al. ${ }^{25}$ using transgenic Drosophilae with a heat shock-inducible CREB repressor isoform (hs-dCREB2-b) showed that flies with the transgene on have impaired memory. Further studies in mice and rats extended these conclusions by showing that while the knockout or knockdown of CREB1 results in longterm memory impairment, viral overexpression of CREB1 in amygdala and hippocampus enable LTM formation from massed training protocols of either cued-fear conditioning or place learning, which normally produce only STM ${ }^{26,27}$. In Aplysia, knockdown of C/EBP impairs long-term memory, while overexpression of C/EBP leads to memory enhancement, similar to that produced by overexpression of CREB1, as short-term facilitation is converted to long-term facilitation ${ }^{28,29}$ Manipulations of C/EBP also lead to memory disruption or enhancement in rats ${ }^{28}$ or mice, as hippocampal knockdown impairs memory, while forebrain expression of a general dominant-negative inhibitor of the C/EBP/ATF family (EGFP/AZIP), which presumably relieves their inhibition, results in enhanced spatial memory $^{30}$.

From the seminal studies that directly acted on CREB1 levels, many other findings followed and have identified memory-enhancing effects that correlate with increases in the activation of the CREB pathway. A natural direction of these studies has been to target activators that are upstream of CREB, such as CAMP, PKA or mitogen-activated protein kinase (MAPK) ${ }^{31}$, though it is interesting to note that in certain cases in which neuronal excitability is altered, a decrease in cAMP signalling may actually be preferable ${ }^{32}$. others have theorized that lifting the inhibition of CREB activation might be an effective route for memory enhancement. For example, in mice, releasing the inhibition provided by calcineurin, a $\mathrm{Ca}^{2+} /$ calmodulindependent phosphatase which regulates pCREB levels, also leads to memory enhancement, via CREB-dependant mechanisms, of both short-term and long-term hippocampaldependent memories, without changing working memory ${ }^{33}$. In Aplysia, inhibition of 
calcineurin facilitates intermediate-term and LTM, but not STM $^{34}$. These studies have been extremely important in gaining an understanding of how memories can be enhanced in an experimental setting by manipulation of CREB levels and/or activity, and imply that the activation of the CREB-dependent pathway might be an effective target for promoting and enhancing hippocampal-dependant LTMs.

There have been a number of attempts to screen for drugs that via CREB activation could potentially be used as cognitive enhancers in humans. These screenings led to the identification of a number of candidate drugs, including rolipram, which inhibits phosphodiesterate type 4 (PDE4), an enzyme that catalyzes hydrolysis of cAMP ${ }^{31,35}$. Additionally, CREB-C/EBP target genes may be valuable candidates for memory enhancement. One $\mathrm{C} / \mathrm{EBP} \beta$-target gene upregulated after learning in the hippocampus and required for memory consolidation is the insulin-like growth factor 2 (IGF-II or IGF-2). Administration of recombinant IGF-II immediately after learning or memory retrieval significantly enhances memory and prevents forgetting ${ }^{36}$. The effect and action of IGF-2 as memory enhancer will be further discussed below. In general, it is important to recognize that, because CREB has important functions throughout the body and diverse effects throughout the brain, an effective treatment based on manipulating CREB or its target genes may require the development of strategies that enhance selectivity and specificity ${ }^{37}$.

\section{Synaptic Remodeling}

Long-term memory formation is critically associated with synaptic remodeling, including the growth or pruning of synapses, as well as altered synaptic efficacy ${ }^{38}$. These changes occur through a number of local regulations, including mRNA translation, protein degradation, remodeling of cytoskeleton, and receptor trafficking into and out of the synapse.

One of the first transgenic manipulations that produced memory enhancement targeted receptor trafficking. In that study, Tang et al. ${ }^{39}$ overexpressed in the hippocampus of mice an $N$-Methyl-D-aspartic acid (NMDA) subunit, NR2B, that had previously been shown to be required for synaptic plasticity and LTM, and found that a number of memories - namely, novel-object recognition, cued and contextual fear conditioning, fear extinction, and Morriswater maze - were all significantly and persistently enhanced. Similarly, later studies showed that if the NR2B subunit was overexpressed in prefrontal cortex, working memory tasks such as the T-maze and a modified water maze were also enhanced ${ }^{40}$. Although it is difficult to parse with a genetic manipulation what stage of the memory is being affected, pharmacological studies indicated that manipulations of NMDA receptors (NMDARs) can enhance both working memory and LTM-consolidation ${ }^{41}$ suggesting that synaptic glutamate receptor expression and trafficking play a significant role in enhancing memory formation and maintenance. Enhancement via NMDARs can be obtained both with agonists and low doses of antagonists ${ }^{42}$, suggesting that a tight regulation of NMDARs is required in order to facilitate memory processes. The mechanisms by which an enhanced NR2B receptor concentration at the synapses leads to memory enhancement is not yet understood. Some insights come from LTP and LTD studies, due to the fact that many similarities exist between the requirements for LTP induction and maintenance and LTM acquisition and consolidation ${ }^{43}$. One theory to explain the memory enhancement effects after increasing NR2B is that they may occur in part by the facilitation of LTP in these regions, whereas overexpression of an alternate subunit, NR2A, facilitates LTD ${ }^{44}$, perhaps because NR2B containing NMDARs are more calcium permeable than NR2A-containing NMDARs. In agreement with this model, partial agonists of NR2B improve memory and enhance LTP in aged rats that have LTP, but not LTD, deficits ${ }^{45}$. 
The ability for NR2B overexpression to result in memory enhancement may occur through the subsequent increased ability of NMDA receptors to be activated due to their increased number. Indeed, partial agonists of NMDARs such as D-cycloserine and D-serine have memory-enhancing effects. D-Cycloserine facilitates long-term fear memory consolidation in humans ${ }^{46}$ and facilitates fear extinction in a rodent model of PTSD, perhaps through normalization of elevated levels of NMDAR subunit mRNA ${ }^{47}$.

Another critical receptor type that has been implicated in memory enhancement is the 2amino-3-(5-methyl-3-oxo-1,2-oxazol-4-yl)propanoic acid (AMPA) receptor. Though, like NMDARs, AMPARs respond to glutamate, they do not have a magnesium block and are therefore activated with less depolarization of the cell. Indeed, AMPARs themselves are required for NMDAR activation, as a synapse without AMPARs (known as silent synapses) will not be able to obtain sufficient depolarization to displace the magnesium block and allow calcium influx ${ }^{48}$. In models of LTP, changes in AMPARS (either through increases in the number of receptors, or changes in receptor effectiveness through phosphorylation) are thought to mediate the long-lasting changes that support LTP maintenance or persistence. For example, inactivation of the atypical protein kinase C isoform M Zeta (PKMzeta) in the amygdala and hippocampus leads to deficits in fear and object recognition memory in rats, which appears to be due to a decrease in post-synaptic GluR2-containing AMPARs ${ }^{49}$. Overexpression of PKMzeta in insular cortex leads to enhancement of conditioned taste aversion memory in rats, and the underlying mechanisms are under investigation ${ }^{50}$. Similarly, long-term memory correlates with an increase in synaptic AMPA receptors, which are known in vitro to be trafficked via the endosomal system ${ }^{51}$. Synthetic compounds, known as Ampakines, which allow glutamate to have a prolonged effect on AMPARs, have been found to strengthen memory retention on a number of tasks and in a number of different species ${ }^{52}$. These compounds have the advantage of passing the blood-brain barrier and of being selective for the central nervous system (CNS).

A number of compounds known to enhance memory are also known to increase NMDAR/ AMPAR levels ${ }^{53-55}$. However, there is still little known about which subunits are increased at different stages of memory. One mechanism of action could be that NMDARs activate CREB and set in motion the gene expression changes discussed above. These changes would then lead to morphological modifications at the synapse, including growth of new spines and increased AMPAR insertion (Figure 3). It is possible that these synaptic changes may represent the endpoint of many memory enhancers. Hence targeting receptor expression may be a general approach to achieve memory enhancement.

One regulatory protein that seems to be linked to receptor trafficking regulation and is induced by learning and required for memory consolidation is the immediate early gene Arc. A number of studies have linked in particular Arc to NMDA/AMPA receptor trafficking ${ }^{48}$ and memory enhancement ${ }^{36,56}$. In vitro studies have shown a role for Arc in removal of Glur1 from synapses, and recent works shows that Arc may in fact be tagged to inactive synapses to depress them during memory formation ${ }^{57}$. Synaptic remodeling leading to memory enhancement does not only refer to changes in synaptic receptors. More global, morphological changes of the synaptic architecture have also been shown to correlate with memory enhancement. Rho-GTP-ases, which lead to remodeling of the actin cytoskeleton, enhance memory when rendered constitutively active by Cytotoxic necrotizing factor 1 (CNF1), a protein toxin from Escherichia coli ${ }^{58}$. Similarly, cell adhesion molecules such as neural cell adhesion molecule (NCAM), which are involved in the remodeling of neural circuits, have been successfully targeted for memory enhancement in rodents, via a mimetic peptide that interacts with the fibroblast growth factor receptor (FGFR) ${ }^{59}$. There are also suggestions that changes in spine shape and size may correlate with memory formation, as LTP is associated with increases in stable, mushroom-shaped spines ${ }^{60}$, but direct causative 
knowledge about how changes in spine morphology relate to memory in general, and specifically to memory enhancement, are still lacking.

\section{Neuromodulation}

Neuromodulators, which alter cellular and synaptic properties via widespread projections ${ }^{61}$ have a well-known role in memory function and many modulation pathways have been targeted for memory enhancement ${ }^{62}$.

One neuromodulator with a well-known effect on cognition is dopamine. Dopamine action is particularly evident in patients who suffer from PD, which involves a loss of dopaminergic neurons and consequently severe motor deficits. The loss of dopamine is also accompanied by a noticeable cognitive impairment in many patients, who are diagnosed with dementia as the disease progresses ${ }^{63}$. However, even in PD patients without dementia, many cognitive domains appear to be impaired during neuropsychological examination. In contrast with many other diseases of cognitive impairment, PD is specifically accompanied by deficits in tasks associated with prefrontal cortex, including executive function and planning, rather than with memory consolidation impairments ${ }^{14}$. Dopamine is thus widely thought to be extremely important for working memory tasks relying on the prefrontal cortex (PFC), and low levels of dopamine receptor D1 (DRD1 or D1) antagonists enhance working memory as revealed by an increase in neuronal activity during a delay period of a delayed-non-match-to-sample task, whereas high levels of antagonists and agonists both impair that activity ${ }^{64}$. Hence, there is an inverted-U curve effect of dopamine on working memory. However, the effects of dopamine on working memory may be restricted to improvement of conditions compromised in dopamine function, as the same treatments in young animals do not show memory enhancement that is seen in aged animals ${ }^{65}$. The effects of dopamine alterations on LTM have been given less attention. An early study showed that dopamine itself given i.c.v. to mice after training enhanced step-through IA at $24 \mathrm{~h}^{66}$, and recently, the D1 agonist SKF38393 given i.p. post-training was shown to enhance $24 \mathrm{~h}$ and $72 \mathrm{~h}$ memory of novel object recognition in rats ${ }^{67}$. Many of the behavioral results are complemented by electrophysiological data showing that AMPA and NMDA currents are enhanced by the injection of a D1/D5 agonist in the hippocampus ${ }^{68}$.

It has long been known that emotional events are better remembered than non-emotional events. Therefore, other neuromodulators that are particularly important for memory are the stress hormones corticosteroids and adrenaline, which are released during arousing experiences. Corticosteroids can activate two receptors - glucocorticoid (GR) and mineralocorticoid (MR). While MRs have a very high affinity for corticoids and are therefore tonically activated, GRs have a much lower affinity and are therefore preferentially activated in conditions of high stress. Manipulations of both receptors have effects of memory, but the behavioural effects of GR have been better characterized ${ }^{55}$. Thus, when cortisol (in humans) or corticosterone (in rodents) is released in concert with a stressful experience, memory is better recalled at later times ${ }^{69}$. The enhancing effect of cortisol administration can be obtained via behavioral methods of inducing stress as well, a this is thought to be a key mechanism regulating intrusive memories that occur with post-traumatic stress disorder $(\mathrm{PTSD})^{70}$. However, it is also known that very intense or prolonged stress may cause memory impairments, as may be the case with intense physical exertion such as occurs with marathon runners ${ }^{71}$. Experimentally, this effect is known as the inverted-U effect of stress on performance, and is seen in animal models as well. Moderate to high stress produce a robust memory in rodents, whereas extremely high stress results in low memory retention. Many studies conclude, however, that glucocorticoids can only enhance memories that inherently involve emotional arousal. Animals tested in a novel context for object recognition show memory enhancement via corticosterone administration, whereas animals that underwent habituation to the context prior to training did not show 
enhancement with corticosterone ${ }^{72}$. Likewise, administration of noradrenaline after training enhances memory retention ${ }^{73}$ which likely occurs through the activation of beta-adrenergic receptors, subsequent activation of adenylyl cyclase, PKA and $\mathrm{Ca}^{2+} /$ calmodulin-dependent protein kinases II (CAMKII). Thus, specific agonists of $\beta$-adrenergic receptors enhance memory, similarly to what occurs via increased arousal during encoding. Noradrenaline is produced primarily in the locus coeruleus and adrenal medulla and many enhancing effects of other modulators, such as glucocorticoids, are critically regulated by the activity of noradrenaline in the amygdala, as suggested by classical studies of Roozendaal et al. showing that a $\beta$-adrenergic receptor antagonist infused into the amygdala blocks memory enhancement produced by glucocorticoids infused into the hippocampus ${ }^{74}$.

In line with all these findings, a number of stimulant drugs that work on inhibiting monoamine reuptake, including amphetamines, methylpehidate $\left(\operatorname{Ritalin}^{\circledR}\right)$ and modafinil (Provigil ${ }^{\circledR}$ ), have been found to improve cognitive function in patients with attention-deficithyperactive-disorder (ADHD), and there have been reports of improved function in healthy subjects as well. Recently, methylphenidate was tested on human subjects who learned a list of words; immediate recall did not differ, but delayed recall, 1 day to 1 week later, showed improvement at two doses ${ }^{75}$.

Though prior studies did not find the same effect, the authors note that this may be due to shorter word lists that were used which may have produced a ceiling effect. Regardless, methylphenidate is well known to have pronounced effects on spatial working memory and sustained attention ${ }^{76}$. The same is generally thought to be true of modafinil, which is traditionally prescribed for narcolepsy. Some studies indicate that positive effect on cognition may be due to increased arousal and attention rather than enhancement of LTM or consolidation processes ${ }^{10}$. Thus, modafinil may be effective in treating specific aspects of cognitive dysfunctions that target attention rather than memory.

Acetylcholine is perhaps one of the most well-studied neuromodulators in the context of hippocampal-dependant memory, and the acetylcholine theory of memory enhancement has been studied for many years. Acetylcholine is required for memory formation, as observed by lesion studies as well as pharmacological inhibition of acetycholine nicotinic and muscarinic receptors. Focusing on memory enhancement, a number of agonists of these receptors have been targeted with varying results ${ }^{77}$. Moreover, observations in laboratory mice that inhibiting acetylcholine uptake could enhance memory led to drugs designed to inhibit the enzyme responsible for degrading acetylcholine, acetycholinesterase. These drugs, namely donepezil (Aricept ${ }^{\circledR}$ ) are now the only available treatment for mild- to moderate- AD. Meta-analyses of the clinical trials studies indicate that although there are benefits of these drugs, the magnitude of their benefit is limited because they offer symptom relief without modifying the disease ${ }^{78}$. Moreover, the beneficial effects are possibly restricted to attention processes rather than enhancing consolidation mechanisms, and may in fact impair memory consolidation by maintaining consistently high levels of cholinergic activity 77,79 .

\section{Endogenous Substances}

The effects on memory enhancement discussed above are mainly the results of pharmacological manipulations with synthetic compounds, especially for those used in clinical studies, as is the case with Ampakines, D-Cylcoserine, and Donepezil. However, a number of endogenous substances, primarily those that are key players in metabolic processes (ie. glucose and insulin), have been known to have a direct memory enhancing effect for quite some time. 
Early studies showing that recently fed subjects performed better than those who had not eaten for some time piqued a long-lasting interest in whether glucose administration can enhance memory functions ${ }^{80}$. Subsequently, a wealth of studies examined glucose-mediated memory enhancement, in both animal models as well as humans due to the relative ease and safety of glucose administration.

Though there have been contrasting findings ${ }^{81,82}$, the majority report that in healthy, young adult rodents and humans memory is enhanced by glucose given pre- or post- training, indicating that glucose may be able to facilitate both encoding and memory consolidation, thought in healthy individuals this may be true only when task demands are high ${ }^{83}$. Importantly, in humans, the vast majority of studies use participants that have fasted for at least 2 hours to overnight before training, indicating that many of the effects seen might actually be indicating that glucose deprivation is deleterious, rather than enhancement by glucose itself. The enhancing effects of glucose was mainly found on declarative, hippocampal-dependant memories tested at relatively early time points (up to $24 \mathrm{~h}$ ) after training ${ }^{84}$. The effects of glucose administration on cognitively-impaired individuals vary, revealing that individuals with very mild problems may have a longer-lasting enhancement by glucose, but those who have already a progressed disease do not show a sustained memory enhancement ${ }^{83}$.

The mechanisms by which glucose enhances memories are not yet entirely understood. A number of studies indicate that the effect may be due to insulin, whose receptors are highly enriched in the hippocampus. In itself, insulin has been shown to enhance hippocampaldependent memories in both rats and humans. However, in rats, insulin-mediated memory enhancement has not been tested past $24 \mathrm{~h}^{85}$ and may not persist up to 1 week after inhibitory avoidance training (Stern and Alberini, unpublished data). Recent studies suggest that insulin may provide memory enhancement also in humans ${ }^{86}$ and several indicate that the enhancing effects of glucose may be due entirely to glucose-stimulated increases in insulin levels ${ }^{87}$. In AD patients, hyperinsulinemia improves performance independent of glucose levels, but hyperglycemia, while maintaining insulin levels at baseline, does not provide the same benefit. Intranasal insulin administration has begun to be tested in patients with mild cognitive impairment and mild-to-moderate AD. In a double-blind study of patients given insulin over 4 months, improvement was seen in a number of measures tested at months 2 and 4 of treatment, as well as two months after treatment was discontinued. The most significant improvement was seen on delayed score recall test (measured with a delay of 20 minutes), but improvements were also seen in a general tests of cognitive ability and partnership scores, a measure of assessment for caretakers of AD patients ${ }^{88}$. These results are very promising, and it would be important if follow-up studies examine memory over longer delays.

In rats, in contrast to glucose and insulin which showed transient effects, a single administration of IGF-II was recently found in our lab to enhance hippocampal-dependant memory for at least three weeks when administered post-training ${ }^{36}$. Furthermore, IGF-II injected into rat hippocampus was found to enhance extinction in mice ${ }^{28,89}$. IGF-II is part of the insulin-like growth factor system, which also includes insulin and insulin-like growth factor I (IGF1 or IGF-I). Interestingly, IGF-I does not seem to have any memory enhancement effect on the tested memories. The memory enhancing effect of IGF-II requires the IGF-II, but not IGF-I, receptor. This is interesting because unlike IGF-I and insulin receptors, IGF-IIR, which is identical to the cation-independent mannose-6phosphate receptor, is not a tyrosine-kinase receptor, but a receptor that targets proteins to endosomes and lysosomal degradation processes ${ }^{90}$. Very little is known about what downstream mechanisms cause this persistent memory enhancement, but due to the receptor requirement and the different temporal dynamics, it seems likely to hypothesize that it uses 
mechanisms distinct from those of insulin or glucose. Interestingly, IGF-II-mediated memory enhancement correlates with increases in synaptic GluA1 receptor at 30 minutes after training, indicating that endogenous targeting of AMPARs may be very effective in promoting memory enhancement. IGF-II may also have an effect on the cholinergic system. In hippocampal neurons, IGF-II potentiates acetylcholine release ${ }^{91}$; therefore, it is possible that an endogenous effect of IGF-II is to potentiate acetylcholine release and action, in addition to regulating other mechanisms. Though very little is known about the role of IGFII in cognitive functions, the ability for IGF-II to pass the blood-brain-barrier ${ }^{92}$ makes it a particularly exciting compound for both preclinical and clinical studies.

Other growth factors, for example brain-derived neurotrophic factor (BDNF), also regulate memory retention. A number of studies have shown increased BDNF mRNA or protein levels following memory enhancement treatments ${ }^{53,93,94}$. However, there seem to be no current evidence that BDNF itself can enhance memory in a non-diseased animal when given close to the time of training, as is the case with IGF-II. However, BDNF appears to increase memory persistence. For example, BDNF injected into the dorsal rat hippocampus 12 hours after an IA training with a low footshock, which produces a memory that would normally be forgotten by 7 days, leads to memory persistence ${ }^{95}$. In disease models, BDNF may reverse memory deficits, making it an attractive candidate for selective enhancement of failing memories.

\section{Behavioral Methods}

In addition to pharmacological approaches, there are a number of behavioral manipulations that have been found to be effective in promoting memory enhancement. First, repetition has long been known to enhance memory performance, and it has been consistently shown that repeated training trials and/or learning events are associated with better memory ${ }^{96}$. This method is one that is employed during everyday learning, and is also known to have benefits for cognitive disorders such as dementia.

Similarly, memory can be enhanced by targeting retrieval-induced reconsolidation, which occurs through repeated retrieval sessions. When a memory is retrieved, it can again return to a labile state and can undergo reconsolidation ${ }^{97}$. It has been suggested that a function of reconsolidation is to increase memory strength ${ }^{98}$. Recently in our laboratory it was found that, in IA, multiple memory reactivation by brief $(10 \mathrm{sec})$ exposures to the context results in memory enhancement in rats through reconsolidation, whereas multiple retrievals consisting of a full testing session can result in fear extinction ${ }^{99}$. Notably memory changes over time, and in order to attain a memory enhancing effect, retrievals must occur within a relatively short time-span after training. Indeed the same multiple 10 second retrievals which had lead to enhancement if given during the first week after training, result in fear-extinction when given 4 weeks post-training, indicating that memory strengthening is a function of the age/ stage of the memory and that likewise, memory storage is dynamic and changes over time. However, there is currently little knowledge about the mechanisms by which these changes occur, or whether the behavioral effect based on reconsolidation would be useful in aging and/or AD.

Interestingly, the reconsolidation process does not promote memory enhancement by behavioral repetitions only. Memory enhancement can be in fact promoted via pharmacological manipulations given in concert with reconsolidation. Thus, injections of nicotine, $\beta$-adrenergic receptor agonists, PKA activators, phosphodiesterase type 5 inhibitors, angiotensin and IGF-II all enhance memory when injected after retrieval $28,100,101$. This suggests that memories can be enhanced even after they are consolidated, and indicates potential new directions for developing treatments for cognitive 
disorders that targets in addition to deficits of encoding/consolidation also deficits of already formed memories.

Another behavioral approach that has been recently found to be effective in enhancing memories is physical exercise. Numerous studies over the past two decades in rodents have shown conclusively that exercise can improve memory in a number of tasks, including the spatial task water maze, the fear task IA and the non-aversive task novel object recognition. This effect may be more pronounced in aged rats, and has numerous possible underlying mechanisms, including increase of the neurotrophin brain derived neurotrophin factor (BDNF), neurogenesis, IGF-I, glucocorticoids, and CAMKII activation ${ }^{94}$, suggesting once again that mechanisms involved in memory consolidation may be the best targets to achieve memory enhancement or prevent memory decay. Though it is generally accepted that exercise is beneficial in regards to general health, extended lifespan and aging, the extent and type of exercise needed in humans to attain a benefit specifically for memory enhancement is not yet mechanistically well understood, and excessive forms of exercise may actually be deleterious for declarative, hippocampal-dependent memories by causing extreme stress, as noted above ${ }^{71}$. Behavioral methods for enhancing memory are an exciting avenue of research, and may be extremely useful in clinical practice with more basic knowledge of how best to implement their practice, as well as whether they can be even further augmented through pharmacological means, as with reconsolidation-mediated enhancement.

\section{Sidebar title Behavioral Tasks in Rodents}

Pavlovian Fear Conditioning pairs an unconditioned stimulus (US), which elicits an automatic response (ie. a mild footshock elicits fear behaviors), with a conditioned stimulus (CS), which has no inherent valance but subsequently elicits the same behavior as the US (ie. a tone). Common versions of this task are auditory fear conditioning (AFC) and contextual fear conditioning (CFC), which pairs a tone and context, respectively, with a footshock. Memory is measured as the $\%$ time spent freezing during the test.

Inhibitory Avoidance (IA) trains the animal to avoid the dark side of a two-chamber apparatus in which it was previously given a footshock. During testing, memory is measured as the latency to enter the dark compartment.

Extinction extends fear-based tasks in which the animal learns through subsequent presentations of the CS without the US that the previously fearful CS is now safe.

Morris Water Maze trains animals to find an escape platform in a circular water maze. Memory during probe trials can be measured as the percentage of time spent in the correct quadrant or latency to find the platform.

Novel Object Recognition (nOR) exploits rodent's natural tendency to explore novel objects. Animals are trained with two identical objects, and during testing, memory is measured as the \% time spent with the novel object. This task can also be modified to ask if animals remember "where" versus "what" by moving one of the objects rather than replacing it with a new object (known as Object Placement).

Radial Arm Maze trains animals to go to specific arms of an 8-arm maze to obtain a food reward. Arms may be cued or contextual cues in the room may guide animals to use the correct strategy to obtain the reward. 


\section{Conclusion}

There are a number of promising avenues in the field of memory enhancement, some of which have been discussed in this Review. There is now a significant amount of information regarding molecular pathways that are likely to be among the most important targets for enhancing memories; however, much remains to be understood to translate this knowledge into clinical trials. For example, most studies in animal models examine effects in males, but a number of studies have shown that there may indeed be sex differences ${ }^{102,103}$. This is an important outstanding question that needs to be addressed further.

The strategies that have promoted memory enhancement in animal models thus far have primarily relied on mechanisms of memory consolidation, such as the CREB-C/EBP pathway and receptor trafficking, which have been mainly studies in aversive or spatial memory tasks. These are mechanisms that are thought to be important for enhancing hippocampal-dependent memories and contrasting cognitive decline in aging and $\mathrm{AD}$. Other studies have focused on the effects of treatments to enhance working memories, such as targeting dopamine neuromodulation that will be useful for diseases such as PD. Importantly, cognitive enhancement therapies may be useful in some situations, but not others. Some may be beneficial in enhancing memory in healthy adults and during normal aging. Others may compensate for disease-related changes, or may instead restore those changes to their original, healthy state. Thus, all potential enhancers must be tested for their mechanisms of action.

One important aspect that remains to be deeply investigated is the question of specificity and flexibility - not all possible memories require or benefit from enhancement, and it is unclear if/when memory enhancement interferes with new learning and the consolidation of new memories. To date, very little attention in animal studies has been given to enhancement of memory retrieval and to enhancement of remote memories, both of which may be important areas of study with very important translational potential.

The study of memory enhancement holds the potential for great progress in the treatment of numerous diseases of the mind, and for developing strategies for more efficient learning and cognitive functions.

\section{Acknowledgments}

Many thanks to Dhananjay Bambah-Mukku, Sarah Johnson, Xiaojing Ye and Michael Garelick for their comments to the manuscript. The writing and part of the work included in this review are supported by the National Institutes of Health (R01-MH074736 and R01-MH065635 to C.M.A. and F31-MH090636 to S.A.S.

\section{References}

1. Alberini CM. Transcription Factors in Long-Term Memory and Synaptic Plasticity. Physiolological Reviews. 2009; 89:121-145.

2. Bliss TVP, Collingridge GL. A synaptic model of memory: long-term potentiation in the hippocampus. Nature. 1993; 361:31-39. [PubMed: 8421494]

3. Ressler KJ, Mayberg HS. Targeting abnormal neural circuits in mood and anxiety disorders: from the laboratory to the clinic. Nature neuroscience. 2007; 10:1116-1124.

4. Lee Y-S, Silva AJ. The molecular and cellular biology of enhanced cognition. Nature reviews. Neuroscience. 2009; 10:126-140.

5. Cooke SF, Bliss TVP. Cellular and Molecular Life Sciences Visions \& Reflections The genetic enhancement of memory. Neuropharmacology. 2003; 60:1-5.

6. Ebbinghaus, H. Memory: A contribution to experimental psychology. Teachers College, Columbia University; 1913. 
7. Cowan N. What are the differences between long-term, short-term, and working memory? Prog Brain Res. 2008; 169:323-338. [PubMed: 18394484]

8. McGaugh JL. Memory--a Century of Consolidation. Science. 2000; 287:248-251. [PubMed: 10634773]

9. Nader K, Einarsson EO. Memory reconsolidation: an update. Ann N Y Acad Sci. 2010; 1191:27-41. [PubMed: 20392274]

10. Lynch G, Palmer LC, Gall CM. The likelihood of cognitive enhancement. Pharmacology, biochemistry, and behavior. 2011; 99:116-129.

11. Simard M, Reekum RV. Memory Assessment in Studies of Cognition-Enhancing Drugs for Alzheimer's Disease. Drugs and Aging. 1999; 14:197-230. [PubMed: 10220105]

12. Carlesimo GA, Oscar-Berman M. Memory deficits in Alzheimer's patients: a comprehensive review. Neuropsychol Rev. 1992; 3:119-169. [PubMed: 1300219]

13. Perry RJ, Hodges JR. Attention and executive deficits in Alzheimer's disease A critical review. Brain. 1999; 122:383-404. [PubMed: 10094249]

14. Dubois B, Pillon B. Cognitive deficits in Parkinson's disease. Journal of Neurology. 1997; 244:28. [PubMed: 9007738]

15. Cansino S. Episodic memory decay along the adult lifespan: a review of behavioral and neurophysiological evidence. Int J Psychophysiol. 2009; 71:64-69. [PubMed: 18725253]

16. Light LL. Memory and aging: four hypotheses in search of data. Annu Rev Psychol. 1991; 42:333376. [PubMed: 2018397]

17. Squire LR. Memory and the hippocampus: a synthesis from findings with rats, monkeys, and humans. Psychological review. 1992; 99:195-231. [PubMed: 1594723]

18. Corkin S, Amaral DG, Gonzalez RG, Johnson KA. Hyman BTHM's medial temporal lobe lesion: findings from magnetic resonance imaging. J Neurosci. 1997; 17:3964-3979. [PubMed: 9133414]

19. White NM, McDonald RJ. Multiple parallel memory systems in the brain of the rat. Neurobiology of learning and memory. 2002; 77:125-184. [PubMed: 11848717]

20. Davis HP, Squire LR. Protein synthesis and memory: a review. Psychological bulletin. 1984; 96:518-559. [PubMed: 6096908]

21. Villers A, Godaux E, Ris L. Long-lasting LTP requires neither repeated trains for its induction nor protein synthesis for its development. PloS one. 2012; 7:e40823. [PubMed: 22792408]

22. Alberini CM. The role of protein synthesis during the labile phases of memory: revisiting the skepticism. Neurobiol Learn Mem. 2008; 89:234-246. [PubMed: 17928243]

23. Sharma AV, Nargang FE, Dickson CT. Neurosilence: profound suppression of neural activity following intracerebral administration of the protein synthesis inhibitor anisomycin. J Neurosci. 2012; 32:2377-2387. [PubMed: 22396412]

24. Bartsch D, Ghirardi M, Skehel PA, Karl KA, Herder SP, Chen M, Bailey CH, Kandel ER. Aplysia CREB2 Represses Long-Term Facilitation : Relief of Repression Converts Transient Facilitation into Long-Term Functional and Structural Change. Cell. 1995; 83:979-992. [PubMed: 8521521]

25. Yin JC, Del Vecchio M, Zhou H, Tully T. CREB as a memory modulator: induced expression of a dCREB2 activator isoform enhances long-term memory in Drosophila. Cell. 1995; 81:107-115. [PubMed: 7720066]

26. Josselyn, Sa; Shi, C.; Carlezon, Wa; Neve, RL.; Nestler, EJ.; Davis, M. Long-term memory is facilitated by cAMP response element-binding protein overexpression in the amygdala. The Journal of neuroscience. 2001; 21:2404-2412. [PubMed: 11264314]

27. Brightwell JJ, Smith Ca, Neve RL, Colombo PJ. Long-term memory for place learning is facilitated by expression of cAMP response element-binding protein in the dorsal hippocampus. Learning \&memory. 2007; 14:195-199. [PubMed: 17351144]

28. Alberini CM, Chen DY. Memory enhancement: consolidation, reconsolidation and insulin-like growth factor 2. Trends in neurosciences. 2012; 35:274-283. [PubMed: 22341662]

29. Lee J-A, Kim H, Kim K, Han J. Overexpression of and RNA interference with the CCAAT enhancer-binding protein on long-term facilitation of Aplysia sensory to motor synapses. Learning and Memory. 2001; 8:220-226. [PubMed: 11533225] 
30. Chen A, Muzzio Ia, Malleret G, Bartsch D, Verbitsky M, Pavlidis P, Yonan AL, Vronskaya S, Grody MB, Cepeda I, et al. Inducible enhancement of memory storage and synaptic plasticity in transgenic mice expressing an inhibitor of ATF4 (CREB-2) and C/EBP proteins. Neuron. 2003; 39:655-669. [PubMed: 12925279]

31. Xia M, Huang R, Guo V, Southall N, Cho M-H, Inglese J, Austin CP, Nirenberg M. Identification of compounds that potentiate CREB signaling as possible enhancers of long-term memory. Proceedings of the National Academy of Sciences. 2008; 106:2412-2417.

32. Wang M, Gamo NJ, Yang Y, Jin LE, Wang XJ, Laubach M, Mazer JA, Lee D, Arnsten AF. Neuronal basis of age-related working memory decline. Nature. 2011; 476:210-213. [PubMed: 21796118]

33. Malleret G, Haditsch U, Genoux D, Jones MW, Bliss TV, Vanhoose aM, Weitlauf C, Kandel ER, Winder DG, Mansuy IM. Inducible and reversible enhancement of learning, memory, and longterm potentiation by genetic inhibition of calcineurin. Cell. 2001; 104:675-686. [PubMed: 11257222]

34. Sharma SK, Bagnall MW, Sutton Ma, Carew TJ. Inhibition of calcineurin facilitates the induction of memory for sensitization in Aplysia: requirement of mitogen-activated protein kinase. Proceedings of the National Academy of Sciences of the United States of America. 2003; 100:4861-4866. [PubMed: 12672952]

35. Tully T, Bourtchouladze R, Scott R, Tallman J. Targeting the CREB pathway for memory enhancers. Nature reviews. Drug discovery. 2003; 2:267-277.

36. Chen DY, Stern Sa, Garcia-Osta A, Saunier-Rebori B, Pollonini G, Bambah-Mukku D, Blitzer RD, Alberini CM. A critical role for IGF-II in memory consolidation and enhancement. Nature. 2011; 469:491-497. [PubMed: 21270887]

37. Barco A, Pittenger C, Kandel ER. CREB, memory enhancement and the treatment of memory disorders: promises, pitfalls and prospects. Expert opinion on therapeutic targets. 2003; 7:101114. [PubMed: 12556206]

38. Lamprecht R, LeDoux J. Structural plasticity and memory. Nature reviews. Neuroscience. 2004; 5:45-54.

39. Tang YP, Shimizu E, Dube GR, Rampon C, Kerchner Ga, Zhuo M, Liu G, Tsien JZ. Genetic enhancement of learning and memory in mice. Nature. 1999; 401:63-69. [PubMed: 10485705]

40. Cui Y, Jin J, Zhang X, Xu H, Yang L, Du D, Zeng Q, Tsien JZ, Yu H, Cao X. Forebrain NR2B overexpression facilitating the prefrontal cortex long-term potentiation and enhancing working memory function in mice. PloS one. 2011; 6:e20312. [PubMed: 21655294]

41. Riedel G, Platt B, Micheau J. Glutamate receptor function in learning and memory. Behavioural brain research. 2003; 140:1-47. [PubMed: 12644276]

42. Danysz W, Zajaczkowski W, Parsons CG. Modulation of leaning processes by ionotropic glutamate receptor ligands. Behavioral Pharmocology. 1995; 6:455-474.

43. Izquierdo I. Pharmacological in memory evidence for a role of long-term potentiation. The FASEB Journal. 1994; 8:1139-1145.

44. Wang D, Cui Z, Zeng Q, Kuang H, Wang LP, Tsien JZ, Cao X. Genetic enhancement of memory and long-term potentiation but not CA1 long-term depression in NR2B transgenic rats. PloS one. 2009; 4:e7486. [PubMed: 19838302]

45. Burgdorf J, Zhang X-1, Weiss C, Matthews E, Disterhoft JF, Stanton PK, Moskal JR. The Nmethyl-D-aspartate receptor modulator GLYX-13 enhances learning and memory in young adult and learning impaired aged rats. Neurobiology of aging. 2011; 21:698-706. [PubMed: 19446371]

46. Kalisch R, Holt B, Petrovic P, De Martino B, Klöppel S, Büchel C, Dolan RJ. The NMDA agonist D-cycloserine facilitates fear memory consolidation in humans. Cerebral cortex. 2009; 19:187196. [PubMed: 18477687]

47. Yamamoto S, Morinobu S, Fuchikami M, Kurata A, Kozuru T, Yamawaki S. Effects of single prolonged stress and D-cycloserine on contextual fear extinction and hippocampal NMDA receptor expression in a rat model of PTSD. Neuropsychopharmacology. 2008; 33:2108-2116. [PubMed: 17957211]

48. Rao VR, Finkbeiner S. NMDA and AMPA receptors: old channels, new tricks. Trends in neurosciences. 2007; 30:284-291. [PubMed: 17418904] 
49. Migues PV, Hardt O, Wu DC, Gamache K, Sacktor TC, Wang YT, Nader K. PKMzeta maintains memories by regulating GluR2-dependent AMPA receptor trafficking. Nature neuroscience. 2010; 13:630-634.

50. Shema R, Haramati S, Ron S, Hazvi S, Chen A, Sacktor TC, Dudai Y. Enhancement of consolidated long-term memory by overexpression of protein kinase Mzeta in the neocortex. Science. 2011; 331:1207-1210. [PubMed: 21385716]

51. Ehlers MD. Reinsertion or degradation of AMPA receptors determined by activity-dependent endocytic sorting. Neuron. 2000; 28:511-525. [PubMed: 11144360]

52. Lynch G. Glutamate-based therapeutic approaches: ampakines. Current opinion in pharmacology. 2006; 6:82-88. [PubMed: 16361116]

53. Slutsky I, Abumaria N, Wu L-J, Huang C, Zhang L, Li B, Zhao X, Govindarajan A, Zhao M-G, Zhuo M, et al. Enhancement of learning and memory by elevating brain magnesium. Neuron. 2010; 65:165-177. [PubMed: 20152124]

54. Hu H, Real E, Takamiya K, Kang M-G, Ledoux J, Huganir RL, Malinow R. Emotion enhances learning via norepinephrine regulation of AMPA-receptor trafficking. Cell. 2007; 131:160-173. [PubMed: 17923095]

55. Krugers HJ, Hoogenraad CC, Groc L. Stress hormones and AMPA receptor trafficking in synaptic plasticity and memory. Nature reviews. Neuroscience. 2010; 11:675-681.

56. McReynolds JR, Donowho K, Abdi A, McGaugh JL, Roozendaal B, McIntyre CK. Memoryenhancing corticosterone treatment increases amygdala norepinephrine and Arc protein expression in hippocampal synaptic fractions. Neurobiology of learning and memory. 2010; 93:312-321. [PubMed: 19932757]

57. Okuno H, Akashi K, Ishii Y, Yagishita-Kyo N, Suzuki K, Nonaka M, Kawashima T, Fujii H, Takemoto-Kimura S, Abe M, et al. Inverse synaptic tagging of inactive synapses via dynamic interaction of Arc/Arg3.1 with CaMKIIbeta. Cell. 2012; 149:886-898. [PubMed: 22579289]

58. Diana G, Valentini G, Travaglione S, Falzano L, Pieri M, Zona C, Meschini S, Fabbri A, Fiorentini C. Enhancement of learning and memory after activation of cerebral Rho GTPases. Proceedings of the National Academy of Sciences. 2007; 104:636-641.

59. Cambon K, Hansen SM, Venero C, Herrero aI, Skibo G, Berezin V, Bock E, Sandi C. A synthetic neural cell adhesion molecule mimetic peptide promotes synaptogenesis, enhances presynaptic function, and facilitates memory consolidation. The Journal of neuroscience. 2004; 24:4197-4204. [PubMed: 15115815]

60. Bourne J, Harris KM. Do thin spines learn to be mushroom spines that remember? Current opinion in neurobiology. 2007; 17:381-386. [PubMed: 17498943]

61. Kupfermann I. Modulatory actions of neurotransmitters. Annual review of neuroscience. 1979; 2:447-465.

62. Floresco SB, Jentsch JD. Pharmacological enhancement of memory and executive functioning in laboratory animals. Neuropsychopharmacology : official publication of the American College of Neuropsychopharmacology. 2011; 36:227-250. [PubMed: 20844477]

63. Mckeith IG, Burn D. Spectrum of Parkinson's Disease, Parkinson's Dementia, and Lewy Body Dementia. Neurologic Clinics. 2000; 18:865-883. [PubMed: 11072265]

64. Williams GV, Goldman-Rakic PS. Modulation of memory fields by dopamine D1 receptors in prefrontal cortex. Nature. 1995; 376:572-575. [PubMed: 7637804]

65. Castner, Sa; Goldman-Rakic, PS. Enhancement of working memory in aged monkeys by a sensitizing regimen of dopamine D1 receptor stimulation. The Journal of neuroscience. 2004; 24:1446-1450. [PubMed: 14960617]

66. Haycock JW, Van Buskirk R, Ryan JR, McGaugh JL. Enhancement of retention with centrally administered catecholamines. Experimental neurology. 1977; 54:199-208. [PubMed: 838012]

67. de Lima MNM, Presti-Torres J, Dornelles A, Scalco FS, Roesler R, Garcia VA, Schröder N. Modulatory influence of dopamine receptors on consolidation of object recognition memory. Neurobiology of learning and memory. 2011; 95:305-310. [PubMed: 21187154]

68. Yang, S-n. Sustained Enhancement of AMPA Receptor- and NMDA Receptor-Mediated Currents Induced by Dopamine D1 / D5 Receptor Activation in the Hippocampus : An Essential Role of Postsynaptic Calcium. Hippocampus. 2000; 10:57-63. [PubMed: 10706217] 
69. McGaugh JL, Roozendaal B. Role of adrenal stress hormones in forming lasting memories in the brain. Current Opinion in Neurobiology. 2002; 12:205-210. [PubMed: 12015238]

70. Yehuda R. Post-traumatic stress disorder. The New England Journal of Medicine. 2002; 346:109_ 114.

71. Eich TS, Metcalfe J. Effects of the stress of marathon running on implicit and explicit memory. Psychonomic bulletin \& review. 2009; 16:475-479. [PubMed: 19451371]

72. Roozendaal B, Okuda S, Van der Zee Ea, McGaugh JL. Glucocorticoid enhancement of memory requires arousal-induced noradrenergic activation in the basolateral amygdala. Proceedings of the National Academy of Sciences. 2006; 103:6741-6746.

73. Gold PE, Ruskirk RVAN. Effects of Posttrial Hormone Injections on Memory Processed. Hormones and Behavior. 1976; 7:509-517. [PubMed: 190105]

74. Roozendaal B, Nguyen BT, Power AE, Mcgaugh JL. Basolateral amygdala noradrenergic influence enables enhancement of memory consolidation induced by hippocampal glucocorticoid receptor activation. Proceedings of the National Academy of Sciences. 1999; 96:11642-11647.

75. Linssen, aMW.; Vuurman, EFPM.; Sambeth, A.; Riedel, WJ. Methylphenidate produces selective enhancement of declarative memory consolidation in healthy volunteers. Psychopharmacology. 2011

76. Advokat C. What are the cognitive effects of stimulant medications? Emphasis on adults with attention-deficit/hyperactivity disorder (ADHD). Neuroscience and biobehavioral reviews. 2010; 34:1256-1266. [PubMed: 20381522]

77. Deiana S, Platt B, Riedel G. The cholinergic system and spatial learning. Behavioural brain research. 2011; 221:389-411. [PubMed: 21108971]

78. Birks J. Cholinesterase inhibitors for Alzheimer's disease (Review). The Cochrane Library. 2009

79. Prickaerts J, Sik A, van der Staay FJ, de Vente J, Blokland A. Dissociable effects of acetylcholinesterase inhibitors and phosphodiesterase type 5 inhibitors on object recognition memory: acquisition versus consolidation. Psychopharmacology. 2005; 177:381-390. [PubMed: 15630588]

80. Lapp JE. Effects of Glycemic Alterations and Noun Imagery on the Learning of Paired Associates. Journal of Learning Disabilities. 1981; 14:35-38. [PubMed: 7229533]

81. Azari NP. Psychopharmacology Effects of glucose on memory processes in young adults *. Psychopharmacology. 1991; 105:521-524. [PubMed: 1771220]

82. Foster JK, Lidder PG, Sünram SI. Glucose and memory: fractionation of enhancement effects? Psychopharmacology. 1998; 137:259-270. [PubMed: 9683004]

83. Smith, Ma; Riby, LM.; Eekelen, JAMV.; Foster, JK. Glucose enhancement of human memory: a comprehensive research review of the glucose memory facilitation effect. Neuroscience and biobehavioral reviews. 2011; 35:770-783. [PubMed: 20883717]

84. Gold PE, Vogt J, Hall JL. Glucose effects on memory: behavioral and pharmacological characteristics. Behavioral and neural biology. 1986; 46:145-155. [PubMed: 3767828]

85. McNay EC, Ong CT, McCrimmon RJ, Cresswell J, Bogan JS, Sherwin RS. Hippocampal memory processes are modulated by insulin and high-fat-induced insulin resistance. Neurobiology of learning and memory. 2010; 93:546-553. [PubMed: 20176121]

86. Benedict C, Hallschmid M, Hatke A, Schultes B, Fehm HL, Born J, Kern W. Intranasal insulin improves memory in humans. Psychoneuroendocrinology. 2004; 29:1326-1334. [PubMed: 15288712]

87. Craft S, Asthana S, Newcomer JW, Wilkinson CW, Matos IT, Baker LD, Cherrier M, Lofgreen C, Latendresse S, Petrova a, et al. Enhancement of memory in Alzheimer disease with insulin and somatostatin, but not glucose. Archives of general psychiatry. 1999; 56:1135-1140. [PubMed: 10591291]

88. Craft S, Baker LD, Montine TJ, Minoshima S, Watson GS, Claxton A, Arbuckle M, Callaghan M, Tsai E, Plymate SR, et al. Intranasal insulin therapy for Alzheimer disease and amnestic mild cognitive impairment: a pilot clinical trial. Archives of neurology. 2012; 69:29-38. [PubMed: 21911655]

89. Agis-Balboa RC, Arcos-Diaz D, Wittnam J, Govindarajan N, Blom K, Burkhardt S, Haladyniak U, Agbemenyah HY, Zovoilis A, Salinas-Riester G, et al. A hippocampal insulin-growth factor 2 
pathway regulates the extinction of fear memories. The EMBO journal. 2011; 30:4071-4083. [PubMed: 21873981]

90. Roth, Ra. Structure of the receptor for insulin-like growth factor II: the puzzle amplified. Science (New York NY). 1988; 239:1269-1271.

91. Hawkes C, Jhamandas JH, Harris KH, Fu W, MacDonald RG, Kar S. Single transmembrane domain insulin-like growth factor-II/mannose-6-phosphate receptor regulates central cholinergic function by activating a G-protein-sensitive, protein kinase C-dependent pathway. The Journal of neuroscience : the official journal of the Society for Neuroscience. 2006; 26:585-596. [PubMed: 16407557]

92. Reinhardt RR, Bondy CA. Insulin-Like Growth Factors Cross the Blood-Brain Barrier. Endocrinology. 1994; 135:1753-1761. [PubMed: 7525251]

93. Lynch G. Memory enhancement: the search for mechanism-based drugs. Nature neuroscience. 2002; 5(Suppl):1035-1038.

94. van Praag H. Exercise and the brain: something to chew on. Trends in neurosciences. 2009; 32:283-290. [PubMed: 19349082]

95. Bekinschtein P, Cammarota M, Igaz LM, Bevilaqua LR, Izquierdo I, Medina JH. Persistence of long-term memory storage requires a late protein synthesis- and BDNF- dependent phase in the hippocampus. Neuron. 2007; 53:261-277. [PubMed: 17224407]

96. Pinsker HM, Hening WA, Carew TJ, Kandel ER. Long-term sensitization of a defensive withdrawal reflex in Aplysia. Science. 1973; 182:1039-1042. [PubMed: 4748675]

97. Alberini CM, Milekic MH, Tronel S. Mechanisms of memory stabilization and de-stabilization. Cellular and molecular life sciences : CMLS. 2006; 63:999-1008. [PubMed: 16596332]

98. Sara SJ. Strengthening the shaky trace through retrieval. Nature reviews. Neuroscience. 2000; 1:212-213.

99. Inda MC, Muravieva EV, Alberini CM. Memory retrieval and the passage of time: from reconsolidation and strengthening to extinction. The Journal of neuroscience : the official journal of the Society for Neuroscience. 2011; 31:1635-1643. [PubMed: 21289172]

100. Dębiec J, Bush DEa, LeDoux JE. Noradrenergic enhancement of reconsolidation in the amygdala impairs extinction of conditioned fear in rats--a possible mechanism for the persistence of traumatic memories in PTSD. Depression and anxiety. 2011; 28:186-193. [PubMed: 21394851]

101. Tian S, Huang F, Li P, Li Z, Zhou S, Deng H, Yang Y. Nicotine enhances contextual fear memory reconsolidation in rats. Neuroscience letters. 2011; 487:368-371. [PubMed: 21035521]

102. Leuner B, Shors TJ. New spines, new memories. Mol Neurobiol. 2004; 29:117-130. [PubMed: 15126680]

103. Mizuno K, Giese KP. Towards a molecular understanding of sex differences in memory formation. Trends Neurosci. 2010; 33:285-291. [PubMed: 20356635] 


\section{Box A. Behavioral Tasks in Rodents}

Pavlovian Fear Conditioning - An task pairing an unconditioned stimulus (US), which elicits an automatic response (ie. a mild footshock that elicits fear behaviors), with a conditioned stimulus (CS), which has no inherent valance but subsequently elicits the same behavior as the US (such as a tone). Two common versions of this task are auditory fear conditioning (AFC) and contextual fear conditioning (CFC), which pairs a tone and context, respectively, with a footshock. Memory is measured as the \% time spent freezing during the test.

Inhibitory Avoidance (IA) - A one-trial task in which the animal learns to avoid the dark side two-chamber apparatus in which it was previously given a footshock,. During testing, memory is measured as the mean latency to enter the dark compartment.

Extinction - An extension of fear based tasks in which the animal learns through subsequent presentations of the CS without the US that the previously fearful CS is now safe.

Morris Water Maze - A task of hippocampal-dependant memory in which animals are trained to find an escape platform in a circular water maze. Memory during probe trials can be measured as the percentage of time spent in the correct quadrant..

Novel Object Recognition (nOR) - A non-aversive task which exploits rodent's natural tendency to explore novel objects. Animals are trained with two identical objects, and during testing, memory is measured as the $\%$ time spent with the novel object. This task can also be modified to ask if animals remember "where" versus "what" by moving one of the objects rather than replacing it with a new object (known as Object Placement). 


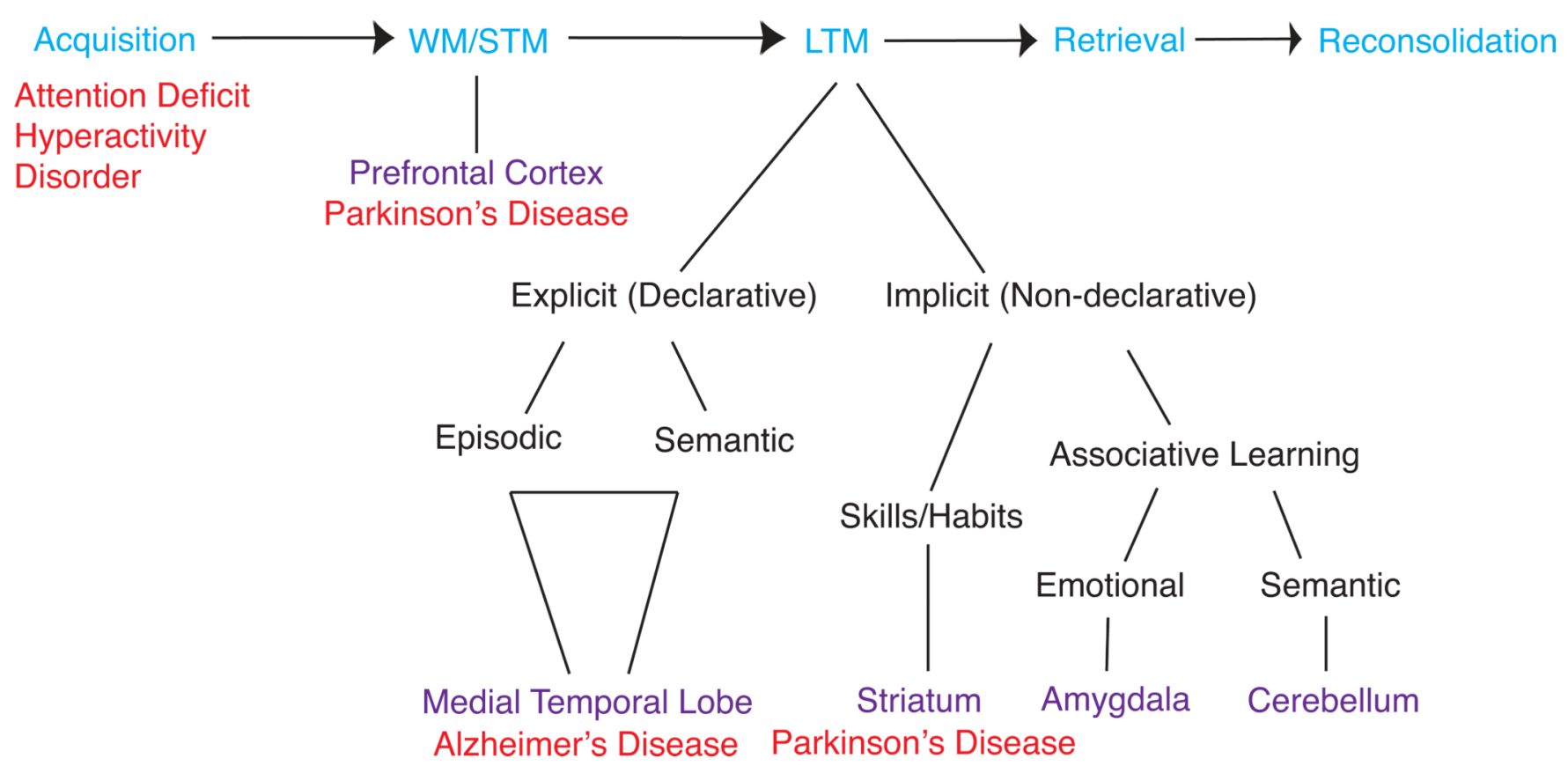

Figure 1. Multiple memory systems as targets of memory enhancement Modified from Squire LR (1992) $)^{17}$

Memory consists of multiple stages and types. A number of different stages (in blue) are involved in acquiring, storing and retrieving a memory. A number of cognitive disorders (in red) have symptoms that are associated with deficits in specific stages, while others may have deficits that are more general or unclear in nature (such as those in cognitive decline over aging). Long-term memory can be subdivided into a number of different types which rely on different brain regions (in purple). Impairments of these different memories are also associated with different disorders. Putative memory enhancers may be associated with the the improvement of a specific stage or memory type, which will therefore affect the clinical population that will receive therapeutic benefit. WM: working memory; STM: short-term memory; LTM: long-term memory. Copyright @ [1992] by the American Psychological Association. Adapted with permission. Squire, L. R. (1992). Memory and the hippocampus: A synthesis from findings with rats, monkeys, and humans. Psychological Review, 99(2), 195-231. doi:10.1037/0033-295X.99.2.195 The use of APA information does not imply endorsement by APA. 


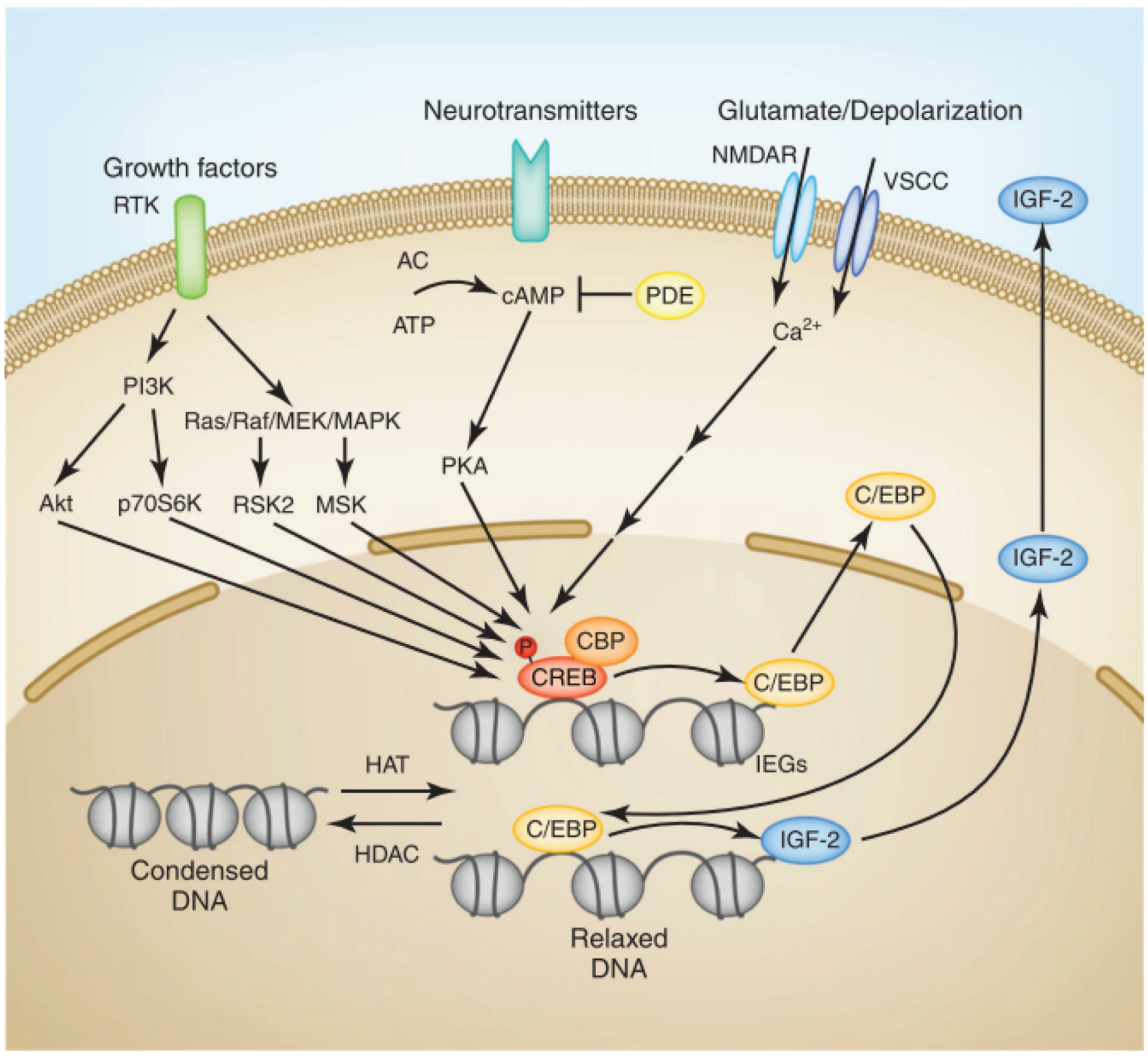

Figure 2. Schematic representation of the CREB-C/EBP pathway targeted for memory enhancement

Taken from: Alberini CM Chen DY (2012) ${ }^{28}$

A number of intracellular signal transduction pathways are activated upon learning by diverse stimuli, such as stress, neurotransmitters, growth factors and membrane depolarization, and lead to activation of the CREB-C/EBP pathway. Growth factors bind to and signal via dimerized receptor tyrosine kinase (RTK), which induces activation of both the Ras/Raf/mitogen-activated protein kinase (MAPK)/MAP kinase kinase (MEK) pathway and the phosphatidylinositol 3-kinase (PI3K)-dependent pathway. Activation of these pathways recruit additional protein kinases, including p90 ribosomal S6 kinase (RSK2) and mitogen- and stress-activated protein kinase (MSK) for the MAPK-dependent pathway and Akt and p70S6 kinase(p70S6K) for the PI3K-dependent pathway to catalyze 
phosphorylation of CREB (pCREB) in its Ser-133 residue, which is an important step for its activation. Another route of CREB phosphorylation is through neurotransmitters binding to their receptors, through which they can couple cAMP by regulating adenylyl cyclase (AC) activity. cAMP recruits protein kinase A (PKA) as the main kinase for CREB phosphorylation. Phosphodiesterase (PDE) can catalyze the hydrolysis of cAMP and inhibit its signaling. Additionally, increases in intracellular $\mathrm{Ca} 2+$ influx through voltage- or ligandgated cation channels, such as voltage-sensitive calcium channels (VSCCs) or NMDA receptors (NMDARs), can also lead to CREB phosphorylation via different calciumdependent protein kinases. Once phosphorylated, CREB recruits its transcription coactivator CREB-binding protein (CBP) to promote transcription of CREB-target genes, such as the immediate early gene, C/EBP. C/EBP, in turn, regulates a number of late-response genes, for example, IGF-II. Targeting any of these upstream pathways in a manner that leads to increased CREB or C/EBP activation, or targeting CREB-C/EBP target genes (as in the case of IGF-II), may in turn lead to long-term memory enhancement. Reprinted from Trends in Neuroscience 35(5), Alberini CM, Chen DY. Memory Enhancement: consolidation, reconsolidation and insulin-like growth factor 2., 274-283 Copyright (2012) 


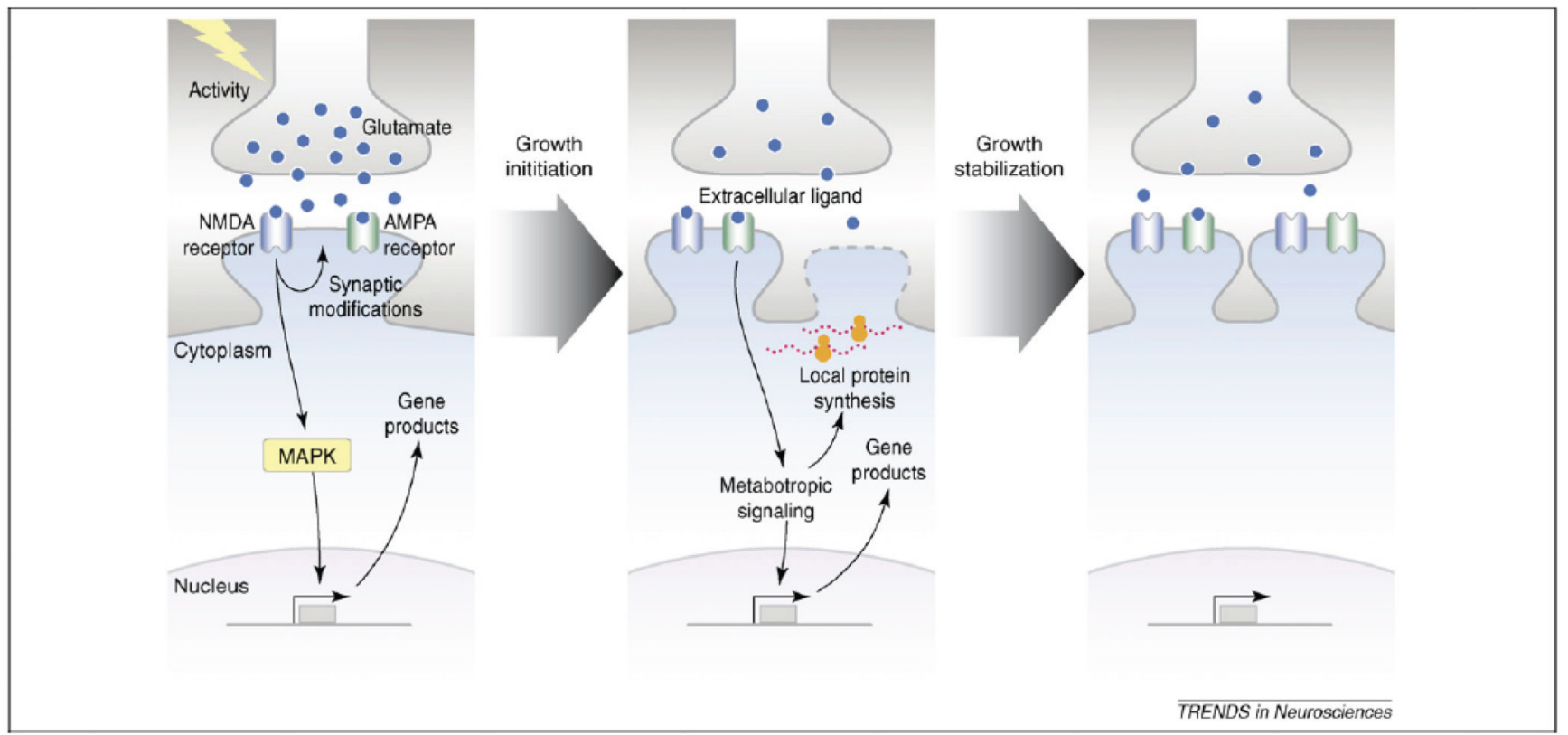

Figure 3. Synaptic remodeling that occurs with learning

Taken from Rao VR and Finkbeiner S (2007) ${ }^{48}$

Presynaptic activity that occurs with learning or stimulation leads to a release of glutamate onto NMDA and AMPA receptors, which depolarizes the membrane. This leads to a number of intracellular changes, including activation of transcription factors, and translation of their downstream targets (Left Panel). These in turn lead to growth initiation, including protein synthesis (for example, of Arc), which then lead to the addition (Middle Panel) and stabilization (Right Panel) of new spines through insertion of new NMDA and AMPA receptors. Targeting synaptic remodeling mechanisms to increase receptor insertion may be an effective route for memory enhancement.

Reprinted from Trends in Neuroscience 30(6), Rao VR, Finkbeiner S. NMDA and AMPA receptors: old channels, new tricks., 284-291. Copyright (2007) 
Table 1

Summary of memory enhancement effects presented in the present review, including species and tasks tested.

\begin{tabular}{|c|c|c|c|}
\hline Name & Species & Tasks & $\begin{array}{l}\text { Relevant } \\
\text { References }\end{array}$ \\
\hline \multicolumn{4}{|c|}{ CREB-C/EBP Pathway } \\
\hline \multirow[t]{2}{*}{ CREB } & Aplysia & Synaptic facilitation & 24 \\
\hline & Drosophila & Conditioned odor avoidance & 25 \\
\hline \multirow{4}{*}{$\begin{array}{l}\text { Downstream } \\
\text { C/EBP }\end{array}$} & Rodent & Fear potentiated startle, water maze & 26,27 \\
\hline & & & \\
\hline & Aplysia & Synaptic Facilitation & 29 \\
\hline & Rodent & MWM & 30 \\
\hline IGF-II & Rodent & IA, CFC, Extinction & 36,89 \\
\hline \multicolumn{4}{|l|}{ Upstream } \\
\hline MAPK & & & 31 \\
\hline PKA & & & 31 \\
\hline cAMP & & & 31 \\
\hline \multirow[t]{2}{*}{ Calcineurin } & Aplysia & Tail-shock sensitization & 34 \\
\hline & Rodent & nOR, MWM, radial arm maze & 33 \\
\hline PDE4 & Rodent & $\mathrm{CFC}$ & 35 \\
\hline \multicolumn{4}{|c|}{ Synaptic Remodeling } \\
\hline \multicolumn{4}{|l|}{ NMDA } \\
\hline & Rodent & nOR, AFC, CFC, Extinction, MWM & 39,47 \\
\hline & & working memory & 40 \\
\hline D-Cycloserine & Human & FC (cued fear conditioning) & 46 \\
\hline \multicolumn{4}{|l|}{ AMPA } \\
\hline \multirow[t]{3}{*}{ Ampakines } & Rodent & $\mathrm{AFC}$ & 52 \\
\hline & NHP & Delayed-non-match-to-Sample & 52 \\
\hline & Human & Delayed Recall & 52 \\
\hline PKMzeta & Rodent & Conditioned Taste Aversion & 50 \\
\hline Arc & Rodent & IA & 36,56 \\
\hline CNF1 & Rodent & MWM, AFC & 58 \\
\hline NCAM & Rodent & MWM, AFC & 59 \\
\hline \multicolumn{4}{|l|}{ Neuromodulation } \\
\hline \multirow[t]{2}{*}{ Dopamine } & Rodent & IA, nOR, Sptial working memory & 66,67 \\
\hline & NHP & Delayed-non-match-to-sample & 64 \\
\hline \multicolumn{4}{|l|}{ Glucocorticoids } \\
\hline \multirow[t]{2}{*}{ Corticosteroid } & Rodents & IA, nOR & 69,72 \\
\hline & Humans & Cued-fear conditioning & 69 \\
\hline Noradrenaline & Rodents & $\mathrm{AFC}, \mathrm{IA}$ & 73 \\
\hline Amphetamines & & & \\
\hline
\end{tabular}

Wiley Interdiscip Rev Syst Biol Med. Author manuscript; available in PMC 2014 January 01. 


\begin{tabular}{|l|l|l|l|}
\hline Name & Species & Tasks & $\begin{array}{l}\text { Relevant } \\
\text { References }\end{array}$ \\
\hline \multicolumn{1}{|l}{$\begin{array}{l}\text { Methylphenidate } \\
\text { Acetylcholine } \\
\text { Donepezil }\end{array}$} & Humans & Delayed Recall, Spatial working memory, Sustained Attention & $10,75,76$ \\
\hline Endogenous & Ruman & MWM, Radial Arm Maze & 77 \\
Glucose & cognitive scales and examinations & 78 \\
Insulin & Rodent & IA & 84 \\
& Human & Verbal Episodic Memory & 83 \\
\hline Behavioral & Rodent & Radial Arm Maze & 85 \\
Reconsolidation & Human & Delayed score recall & 86,87 \\
Exercise & Rodent & IA, AFC, CFC & $28,98,99,100$ \\
\hline
\end{tabular}

